the treatment of the disease to the exhibitors of "globules," the inherent physiological powers of the system are frequently adequate, without assistance, to remove the morbid action and its effects. Too often, however, patients have fallen victims to their own folly in this respect.

It is the distinguished office of the physician to excite, regulate, and otherwise assist these natural actions, by the proper and judicious employment of remedies, the therapeutical properties of which have been accurately ascertained. I contend that there is no disease in which so much can be done to promote a cure, and to prevent a fatal result, as pneumonia. We are far from being reduced to the humiliating position, either of trusting such cases to pharmaceutical cookery and "Sarah Gamps," or abandoning them to the tender management of the homoopathists.

(To be Continued.)

\title{
REVIEWS AND BIBLIOGRAPHICAL NOTICES.
}

1. The Pathology and Treatment of Stricture of the Urethra, both in the Male and the Female. Being the Treatise for which the Jacksonian Prize for the year 1852 was awarded by the College of Surgeons of England. By Henry Thomson, F.R.L.S., M.B., London, \&c. \&c. Pp. 324, and Appendix. London: John Churchill. 1854.

THE subject of stricture of the urethra is one which has called forth the attention and the best energies of many very able surgeons; and great differences of opinion have been entertained and expressed regarding it. Those differences, however, have been chiefly in regard to the plan of treatment, each surgeon advocating his own particular views in this respect, and recommending his own mode of practice. And so long as one set of surgeons maintain that there is no such thing as an impermeable stricture-that, in every case, however narrow the passage may be, an instrument may be forced through into the bladder-while another set hold the contrary opinion, so long must these differences in regard to the mode of treatment continue.

The number of treatises on strictures, of monographs on the perineal section, and pamphlets on the treatment by internal and external incisions, has been of late years very great; but these, so far from reconciling differences of opinion, have only been remarkable for bitter controversy, and not a little acrimonious discussion. Still, however, these may have been so far beneficial to the profession at large, and practically useful to those afflicted with the malady, by bringing into notice, and testing the value of, various modes of treatment for a disease appearing with many shades of character, 
and giving rise to the most distressing symptoms, and, no doubt, requiring different modes of management in different cases. No surgeon will maintain that every case of stricture of the urethra must necessarily require the perineal section for its effectual removal; nor yet that all strictures can be overcome by the common or metallic bougie, by dilatation, ulceration, or by the argentum nitratum, or the potassa fusa. And, on the other hand, few surgeons will deny that the perineal section, or some other mode of getting into the bladder in the first place, and removing the stricture permanently in the second place, becomes absolutely necessary in cases of the disease of long standing, complicated perhaps with abscesses, fistulas, and a broken-down constitution, and which have resisted other and more usual modes of procedure. Much must necessarily depend on the nature and history of the case.under consideration, one plan of treatment being suitable in one instance, while a very different mode will become necessary for another.

In the present work, the author enters very fully into the whole subject of stricture of the urethra. He treats-1. Of the anatomy and physiology of the male urethra, or the anatomical relations of the normal as well as of the diseased urethra, respecting which it is stated, in the preface, that "no pains have been spared in order to develop the best mode of conveying, as far as this can be done on paper, sound information upon this important subject. It will be seen that a great number of bodies have been examined to supply the facts related. One, out of several illustrative preparations which were sent into the College of Surgeons with the essay, contained portions of the corpus spongiosum from not less than twelve bodies, to illustrate a point in its anatomy." 2. The classification, the pathological effects, the causes and diagnosis of stricture of the urethra. And 3. The treatment, which occupies three chapters, and comprehends the treatment by chemical agents, by external incisions and by internal incisions. There are also two chapters upon some of the effects of stricture-viz., urinary abscess, fistula, and retention of urine. The last chapter is devoted to stricture of the female urethra. An Appendix, of more than 100 pages, contains many most interesting and practical notes, and a table of cases, 200 in number, "each containing a very brief statement of the chief incidents in the history of the patient, and his present condition, condensed from fully reported cases only, upon the aggregate of which have been founded, in a great measure, the chapters on 'The Symptoms' and on 'The Causes of Stricture.'"

In a work of such magnitude and extent, upon a subject which has employed the pens of so many authors, we can do little more than give a few extracts from the different chapters, from which our readers will be enabled to judge of the value of the work, and of the manner in which the author has discussed the various points connected with stricture of the urethra. 


\section{The "Anatomy and Physiology of the Male Urethra " is treated} at great length in the first chapter, in which is detailed and minutely described the various parts into which the canal has been divided by anatomists - the prostatic, membranous, spongy, and bulbous portions, together with the glands, rugæ, mucous membrane, blood-vessels, nerves, fasciæ, and muscular tissues connected with the canal; and the observations and opimions of various anatomists are given, thereby rendering this chapter a complete anatomical description of the male urethra. The researches and observations of Sir Everard Home, Mr. Guthrie, Kölliker, Mr. Hancock, Müller, \&c., are detailed, in some instances at great length, and also freely critieised, the author stating his own conclusions briefly and with becoming modesty. As an example, we quote his conclusions respecting the muscles concerned in the act of micturition :-

"There has been some disagreement and want of perspicuity in the statements of physiologists respecting the special functions of the muscles which surround and act upon the urethra, and as it is exceedingly important in relation to our subject to arrive at correct views respecting these functions, I have therefore been led to study them closely, and seek for information by independent observations of my own, the results of which, with the utmost deference to the high authorities from whom I may have been compelled in some particulars to differ, I beg leave to embody in the following statements and eonclusions:-

"That the urethra, in its natural condition, and when not in action, forms a shut passage, the membranous walls of which, for the most part disposed in folds, lie in close approximation to eaeh other, and are so maintained by the agency of contractile structures around.

"That the act of micturition requires for its proper performance a patent condition of the passage, and consequently the complete relaxation of certain muscles, forming a distinct group; viz., the anterior part of the levator ani (levator prostatæ), the compressor urethræ, the accelerator urinæ, ${ }^{*}$ the transversus perinei, and the erectores penis.

"That this act is accomplished by the contractile power of the bladder itself, chiefly and primarily; the diaphragm and abdominal museles eo-eperating to an extent which depends on the amount of force expended on its performance. The whole process in the healthy individual, in ordinary circumstances, always taking place in obedience to, and under the control of, the will.

"That cessation of the act, whether occurring involuntarily, because the bladder is empty, or suddenly by an act of the will, before complete evacuation has takeu place, consists in the accurate closure of the neck of the bladder and urethral canal, through contraction of all the muscles forming the group described, which effort produces also, at the same instant, complete expulsion of the contents of the passage, which would otherwise leave it guttatim." - (Pp. 29, 30.)

And again, in relation to a point connected with hæmorrhage, and which is of much importance in regard to the mode of treatment by external incisions, afterwards considered, it is stated-

"There is a point, however, esteemed of impertance in connection with practice, relating to the internal structure of the corpus spongiosum in the situation of the bulb, which has to be noticed. Owing to the free inosculation of the vascular passages with each other, which appertains to that structure, incisions

" * Hence the term, ' accelerator urinæa,' is a misnomer. The muscle is in a state which is the reverse of action during the process of micturition." 
carried into it have always been regarded as liable to give rise to considerable bleeding. But it has been alleged that the occurrence of this accident is rendered much less probable when such incisions are made strictly in the middle line, inasmuch as, with such precautions, a fibrous partition existing there receives the knife, and defends the vascular structures on either side. Most anatomical writers of the present day agree in affirming the presence of this partition. It is thus desoribed by Ellis:- ' The fibrous covering of this body sends inwards processes to form a network. Moreover, a piece projects inwards in the middle line opposite to the bulb, which reaches forwards to a short distance, and assists in dividing that body into two lobes.' This account appears to be given on the authority of Kobelt, who published it in his work, entitled ‘Die Männlichen und Weiblichen Wollust-Organe,' in 1844. On the other hand, its existence has been wholly denied.* I have, accordingly, embraced several opportunities of making transverse sections of the bulb, and can most unhesitatingly confirm the statement that a partition exists, and may sometimes be traced forwards to within two or three inches of the external meatus. It is distinctly seen, in some instances, to be composed of two layers, with a faint dark line between them, indicating that the coherence of two bodies in the middle line, to form a single corpus spongiosum, is the typical formation, traces of which were present in all the subjects examined to a greater or less extent."

"That the entry of the arterial branch of supply at about a half or threequarters of an inch before the posterior extremity of the corpus spongiosum, renders incisions at this point liable to become the cause of considerable hæmorrhage. That the existence of several fibrous partitions in the part pesterior to the entrance of the artery, and especially one in the middle line, may tend to render incisions into that part of the bulb so defended, less productive of hæmorrhage, than in parts where these do not exist."-(Pp. 38-40.)

In the second chapter, upon the "Classification and Pathology of Stricture," the author begins by giving a definition of the disease, which, however, is not of much importance, provided the thing itself be exactly understood. He divides diseased contractions of the urethra into permanent or organic, and transitory, the latter being either inflammatory or spasmodic, then considers the various modes of classifying strictures which have been adopted by surgeons, the numbers, according to different authors, varying from two to seven. Mr. Thomson gives his reasons for adopting this division, concluding with the advice, that we shall do well " not to attach more importance to mere classification than it deserves, regarding it only as a useful, but subordinate and imperfect, means of contributing to the object we have in view, viz., the right and easy understanding of the subject under consideration."

It is well known by surgeons, that stricture, when it continues long and becomes permanent, producing a continued obstruction to the flow of urine, gives rise to certain anatomical changes in the urinary bladder, particularly hypertrophy of that organ, and, as a consequence, sacculi or cysts :-

"As a consequence of that fasciculated arrangement which the fibres acquire, interstices of varying size are observed between the bundles. These depressions

"* Professor Lizars, in the Medical Times, August 16, 1851, states that he has never seen this septum; that he has recently examined 'two bodies,' ' but could perceive no septum whatever,' and he presents a drawing denoting its absence." 
become deeper, and the mucous membrane being driven in by the fluid pressure which is exerted upon them, is apt, in course of time, to form pouches, which are sometimes of very considerable size. One of these, after long-continued dilatation, may at length form a receptable for the urine, having a capacity as great, or even greater, than that of the original bladder. . . . In some of these pouches it is not rare to find a collection of calculous matter, and in this manner are sometimes formed those encysted calculi which ocicasionally baffle the lithotomist."-(Pp. 65, 66.)

Any one who may read this chapter on the classification and pathology of stricture, must at once admit the great industry and patient perseverance which Mr. Thomson has devoted to the elucidation of the points upon which he writes. We quote the following conclusions at the close of the chapter :-

"In examining the museums named, I have personally submitted to a close and careful inspection of not less than three hundred preparations of stricture of the urethra, of which I possess notes made on the spot of two hundred and seventy, the rest being examples which, from decay or other circumstances, it was impossible correctly to classify.

"These examples may all be comprehended by the three following classes:-

"I.-Strictures occurring at the Sub-Pubic Curvature; $i$.e., at the junction between the spongy and membranous portions and its neighbourhood. ...

" II.-Sirictures occupying the Centre of the Spongy Portion; i. e., a region extending from the anterior limit of the preceding, to within two inches and a half of the external meatus, and measuring, therefore, about two and a half to three inches in length.

" III.-Strictures occurring at the External Orifice, and within a distance of two inches and $a$ half of it.

" Lastly, I may confidently assert that there is not a single case of stricture in the prostatic portion of the urethra, to be found in any one of the publio museums of London, Edinburgh, or Paris. I am disposed to believe that some observers have been deceived in reference to it, or that it owes its supposed existence to inferences drawn from the results of examinations of the living body, which can by no means be admitted as evidence on this subject. Two specimens only of the whole number have at any time been regarded as liable to. be considered prostatic stricture. ..... At present, therefore, the existence of prostatic stricture appears to rest on the observations of Leroy, D'Etiolles, and Ricord. Its excessive rarity, to say the least, is at all events demonstrated. [It is almost unnecessary to add, that enlargement of the prostate, while it sometimes narrows, and frequently renders tortuous, that part of the urethra which passes through the gland, cannot be regarded as coming within the definition of stricture. That organic narrowing of the urethra only which commences within its own walls, and not that which is caused by external tumour, being understood to constitute the stricture which, commonly affecting all other parts of the urethral canal, is not found in its prostatic portion."-(Pp. 87-89.)

In the chapter on the "Diagnosis and Treatment," our author gives minute directions for properly exploring the urethra and examining the stricture, in order to ascertain the nature of the obstruction, whether involving one portion of the canal or several, and whether it be permanent or merely temporary. The various instruments employed for this purpose by different surgeons, with their shapes and other properties, are explained, and their advantages and disadvantages pointed out, Other points absolutely necessary to be considered in the mode of management of strictures are not omitted-as, the use of belladonna, chloroform, rest, 
and regimen, the chemical state of the urine, \&c. All these subjects are treated at length, and we think with much ability, evidently showing that Mr. Thomson has studied the whole carefully, and has acquired much practical experience in regard to them. Respecting the treatment by chemical agents, a short and concise account of the mode of practice adopted by the older surgeons, in their use of the potassa fusa and nitrate of silver, is given, and the conclusions are stated at the end of the chapter.

"That these agents are never to be employed for the sake of their escharotic or caustic powers, properly speaking. That the nitrate of silver, lightly applied, exerts a salutary action on the diseased surface of the urethra, relieving inordinate irritability, and checking undue vascularity and disposition to hæmorrhage, as it does in similar conditions of the skin and mucous membrane in other parts of the body, and thus it becomes a useful adjunct to dilatation. That the potassa fusa, as a caustic, is considerably more active than the preceding, and is, therefore, more dangerous of application. If used at all, it should be only in very minute quantities, such as fractional parts of a grain, inasmuch as it is exceedingly difficult to limit the action of so powerful an escharotic. It may perhaps aid dilatation, and the eradication of some strictures, probably by facilitating the solution of some of their component tissues, when care is taken to employ it in obedience to the condition just named."-(Pp. 220, 221.)

Mr. Thomson is decidedly against the mode of treating stricture by cutting within the urethra, that is, the plan by internal incision - a plan which has been employed to a great extent, and many very ingenious instruments contrived by different surgeons for dividing the stricture. The great objection to all these instruments, and indeed to the plan altogether, is, that the operator has no means of seeing how far or what parts he cuts. Great mischief may result, and has resulted, from this practice, by injuring the parts surrounding the urethra; therefore Mr. Thomson considers it less dangerous " to lay open the perineum, and divide the stricture from without, thus giving free vent to noxious fluids of all kinds, than to wound the urethra from within, at or behind the bulb, as we run great risk of doing, when operating at six inches' distance from the external meatus, and thus only make a channel for these matters into the erectile cavities and other structures around."

Forty pages of this work are taken up in discussing and criticising the treatment by external incisions-a plan which has of late given rise to so much difference of opinion among surgeons. Two hundred years ago, Wiseman relates that a celebrated surgeon, in a case of retention of urine, made an incision "into the urethra, near the neck of the bladder." Some time after, on the same patient, " the whole length, or nearly so, of the urethra, was laid open from without by incision in the middle line, dividing the scrotum." This plan, therefore, of external incision is of old date, and Mr. Thomson details at length the mode of proceeding by various surgeons, from the time of John Hunter, down to the perineal section, or rather the "external division," of Mr. Syme. $\mathrm{Jt}$ is no doubt well known that Mr. Syme does not adopt this 
mode of procedure for the cure of the same kind of cases for which it was employed by the older surgeons, and is still employed by many at the present day. The old operation of cutting in the perineum was had recourse to in cases of stricture in which no instrument could be got through the canal-in impermeable stricture of the urethra. Mr. Syme considers there is no such case, and such an operation therefore is always unnecessary and improper. His operation consists in dividing the stricture from the perineum, upon a grooved sound previously introduced into the bladder. Hence Mr. Thomson very properly distinguishes Mr. Syme's mode of operating by the term "external division," the phrase "perineal section" having been long employed to point out a different plan of operating, and in the treatment of a different class of cases. Mr. Syme's operation is, "external division, as a curative means for certain strictures which admit the passage of a sound." Mr. Syme's opinions are here discussed in a great spirit of fairness, and the writer seems more disposed to coincide with his views than are many eminent surgeons of the present day. After asserting that it is an incontrovertible fact, that the urethra is sometimes completely obliterated, he states the case in regard to impermeable stricture thus :-

"In the controversy which has been maintained on the subject, the oversight of a very simple fact has led to much unnecessary discussion. This I will endeavour to make apparent. Mr. Syme denies the existence of 'impermeable stricture,' declaring that he has never met with one through which, the urine passing outwardly from the bladder, he has not been able fairly to pass an instrument in. He has been supposed to deny the existence of an obliterated urethra. This, however, he seems never to have done, so far as I am able to judge. But it appears that, in the North especially, a distinction is made between stricture and traumatic obliteration, which is not invariably recognised here. . . . Mr. Liston was accustomed to draw the same distinction. In a clinical lecture given during the winter session of 1835-6, he used the following words :- 'It has been proposed in what are called 'impassable strictures ;' but there are no strictures impassable that I have ever seen, for where any water comes away you can, by patience and perseverance, get a catheter through sooner or later, to introduce, \&c.' . . . . At this time Mr. Liston had never performed any operation for retention of urine beyond the passing of a catheter. He was compelled, however, on one occasion afterwards, to puncture the bladder, as well as to perform perineal section several times in cases of ordinary stricture, in which he failed to pass a catheter, and then he adopted precisely the same operation which has been referred to as recommended and deseribed by Mr. Guthrie, and the directions for performing which he gave in his 'Operative Surgery.' Sir B. Brodie also recognises, to some extent, the same distinction, as may be seen by reference to his work.

"From the numerous pathological facts afforded by our museums, it appears then that obliteration of the urethra does exist; that it is unquestionably exceedingly rare; lastly, that it is very doubtful if strictures which are not of traumatic origin ever arrive at that condition. We have no evidence at least to show that they do.

"Mr. Syme's assertion then amounts to this, and can be understood to mean no more, viz., that wherever the urine passes out by the external meatus, a catheter may be got in. Thus he writes: 'As to the question of 'impermeability,' I simply maintain, that if the urine passes out, instruments may always, through 
care and perseverance, be got in beyond the contraction. It should be observed that the case here is quite different from that of a distended bladder requiring immediate relief. I have never maintained that in such circumstances the introduction of a catheter was always practicable,' \&c. And I think that there are few surgeons who possess experience and dexterity in the use of the catheter who will deny the truth of this axiom as a rule; and such, if repeated opportunities are afforded of making the trial, will succeed in overcoming very nearly all the cases which eome before them by fair means. . . . Nevertheless, taking the broadest view of the subject, regarding the fact that men of known and acknowledged ability and great experience have now and then failed, I shall not dare to assert the impossibility of occasional exception to this rule. . . Most assuredly the cases are few, in which a sound may not be passed by a skilful and persevering operator, perhaps fewer than they have generally been supposed. For my own part, I am free to confess that I have assuredly learned one thing; viz., that confidence in the power of the catheter, and perseverance in its use, constitute the secret of successful practice in its application. I can only not venture to assert, that whatever may have been my fortune hitherto, some future experience may not compel me to admit the existence of impermeable stricture, although it be manifest, at the same time, that total obliteration does not exist." -(Pp. 248-52.)

We cannot dwell longer upon this subject, or quote further from Mr. Thomson's treatise. He seems to advocate Mr. Syme's operation, and to consider it an improvement upon the other means of treating this very painful affection. Out of 120 cases in which the operation has been performed, seventy times by Mr. Syme himself, the remainder by various surgeons, four deaths only occurred, none of which were in Mr. Syme's practice ; and in regard to these it is stated-"On examining attentively the circumstances of these, it does not appear that death was caused by any accident necessarily connected with, or peculiar to the operation, but by one which is known to attend incisions or lacerations of any kind." "The cause of death was undoubtedly pyohœmia: it was not hæmorrhage ; and although much has been said respecting this, I believe it has never been directly stated by any writer to have been so in a single instance." Further, with respect to hæmorrhage, Mr. Thomson states that he was determined to ascertain the facts relating to it in connection with the cases operated on, and having done so, he says-" I have no hesitation in affirming, after a full examination of the evidence relating to Mr. Syme's cases, that the statements which have been made by some writers respecting hæmorrhage have been greatly exaggerated, if not, in one or two instances, wholly unsupported by facts."

The subject of the treatment by external incisions is concluded by the following remarks:-

" In bringing the consideration of this subject to a close, I confess that these remarks have become extended beyond the limit of the original design, notwithstanding every effort on my part to render them as succinct as possible. But $I$ have felt impelled to discuss the subject fully, if at all. In the present state of divided opinions, and conjectures respecting it, it was impossible to escape the

"* For those who desire to see a considerable portion of the evidence in relation to this subject, condensed and presented in one view, see 'British and Foreiga Medico-Chirurgical Review,' 1851, No. XV., Article viii." 
duty of making a laborious, careful, and, as far as possible, unprejudiced exami nation of the evidence presented in relation to the subject, unless, indeed, its consideration were given up altogether, an alternative which could not for a moment be entertained. I have been compelled to arrive at conclusions somewhat at variance, perhaps, with my own preconceived notions; but I have the satisfaction of believing, that a fair and correct exposition of this much ' vexed question' has been presented, as the result of what has certainly been the most arduous portion of my labours in relation to this work. I have at least performed it with most honest intentions to eliminate the truth, as far as has been possible; whether altogether successfully or otherwise, time only, as it augments our experience, can determine."-(P. 275.)

We have no space left to consider the remaining chapters on "Urinary Abscess and Fistula," "Retention of Urine depending on Stricture," and on "Stricture of the Female Urethra," which are treated at considerable length, in a manner highly creditable to the author's talents and industry. Indeed we do think that Mr. Thomson has discussed all the points connected with stricture of the urethra with great ability, so that his treatise is one of much practical interest, and cannot fail to be useful to the profession. It amply justifies the College of Surgeons in awarding to him the Jacksonian prize.

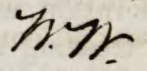

\section{The Pathology and Treatment of Leucorrhaea. By W. TrLeR SмITH, M.D. London : 1855.}

In recent times there has, in the whole range of medicine, been no more fruitful source of polemical discussion than leucorrhøa. The reintroduction in the present century of the use of the speculum matricis into ordinary practice, revealed to obstetricians a new set of recondite lesions. The greatly increased frequency of physical examination of the female organs to which this gave rise, resulted in the proclamation, if not in the discovery, of various new disorders of these parts. The examinations necessary for their investigation were easy to men of the meanest capacity. The new field of practice was, as might be expected, entered upon with the greatest zeal and alacrity by a crowd of doctors. The cases were all in a class, having the greatest development of our common emotional feelings, but having also the peculiar weaknesses implied in the very name of woman. In such a field, it was not to be wondered at that enthusiasm should be engendered; it was much to be lamented that this should so soon have degenerated, in the case of many physicians, into great imprudence, and in not a few into gross charlatanry. Women, enervated by luxury, overpowered by hysteria, or weakened by disease-new doctors ascribing all sorts of complaints to disorder or disease of the womb -new diseases found to be alarmingly frequent, inflammation, ulceration, eruptions, hypertrophy, engorgement, displacement, 